\title{
Smoking-induced chromosomal segregation anomalies identified by FISH analysis of sperm
}

\author{
Ciro Silveira Pereira', Maria Silvina Juchniuk de Vozzi ${ }^{1}$, Silvio Avelino dos Santos ${ }^{1}$, Maria Aparecida C Vasconcelos ${ }^{2}$
} Cláudia CP de Paz', Jeremy A Squire ${ }^{1,3}$ and Lucia Martelli ${ }^{1 *}$

\begin{abstract}
Background: Numerical chromosome aberrations in gametes are directly related to infertility and aneuploid embryos. Previous studies have shown that toxic substances from cigarette smoke induce structural and numerical chromosomal aberrations in vitro and could potentially increase levels of aneusomy in sperm. Moreover, increased levels of aneusomy in sperm are correlated with low implantation rates, spontaneous abortions and fetal losses. Studies of chromosome 3 in sperm suggest it may be more prone to segregation anomalies than other autosomes, but there has been no systematic investigation of the incidence of disomy for chromosome 3 in sperm derived from donor male smokers. The objective of this study was to use FISH to evaluate the influence of smoking on the levels of disomy for chromosomes $X$ and $Y$, and to determine whether disomy levels for chromosome 3 were elevated in sperm derived from male smokers.
\end{abstract}

Results: FISH analysis was used to evaluate the frequency of disomies of chromosomes 3, X, and $\mathrm{Y}$ in sperm of 10 smokers, compared to a control group of 7 non-smoking fertile men. All the subjects presented a normal somatic karyotype. There was a significant increase in the overall frequency of disomies in sperm derived from the smoking group $(P<0.0001)$. When each chromosome pair was analyzed individually, disomy of chromosome 3 in smokers was found to be more than twice that observed in the matched non-smoker control group. In addition we observed a higher frequencies of disomy of the $X$ and $Y$ chromosomes, indicating elevated levels of diploidy in the sperm from the smoking group.

Conclusions: In this study we have shown that chromosome 3 may be susceptible to smoking-related segregation anomalies. Our results also suggest that errors can occur in both meiosis I and II, confirming the emerging literature that the male meiotic process may generally be affected by the genotoxic damage from tobacco use. Collectively, these findings provide additional evidence for enhancing tobacco control measures, and suggest that FISH analysis of chromosome 3 in sperm may be useful for monitoring smoking-induced segregation damage as part of the evaluation of infertile males.

Keywords: Tobacco consumption, Sperm, FISH, Meiosis, Male gametogenesis, Disomy, Male infertility, Aneuploidy, Non-disjunction

\section{Background}

Numerical chromosome abnormalities are directly related to infertility. Approximately 35\% of spontaneous abortions in the first trimester are caused by some chromosomal anomaly [1]. Errors in paternal meiosis are responsible for about $5-10 \%$ of autosomal aneuploidies;

\footnotetext{
* Correspondence: Irmartel@fmrp.usp.br

'Department of Genetics, Ribeirao Preto Medical School, University of São Paulo, 3900 Bandeirantes Avenue, Zip code 14049-900 Ribeirao Preto, SP, Brazil

Full list of author information is available at the end of the article
}

for nearly $50 \%$ of $47, \mathrm{XXY}$; for $70 \%$ of $45, \mathrm{X}$; and for all of the $46, \mathrm{XYY}$ sex chromosome anomalies [2].

Advanced maternal age still remains as one of the few well-established risk factors. Other potential contributors to aneuploidy include alcoholism, occupational exposure to pesticides, and smoking [3]. The World Health Organization [4] estimates that about one-third of the male population smokes. Furthermore, cigarettes contain more than 400 toxic substances and more than 4,000 different chemicals with unknown physiological consequences. Exposure to tobacco smoke has been 
experimentally shown to induce cellular DNA damage and numerical and structural chromosomal anomalies in mammalian and prokaryotic models, including in vitro and in vivo systems [5-7].

Honein and colleagues [8] observed a positive association between maternal smoking and birth defects, including hydrocephaly, microcephaly and oral clefts. Recently, significant associations with maternal smoking were also found for cardiovascular/heart defects, musculoskeletal defects, limb reduction and other birth defects [9].

Furthermore, in vitro studies confirmed that amniocytes obtained from pregnant women and cultured in medium containing nicotine showed high frequencies of structural and numerical chromosomal aberrations, involving chromosomes $21,22,8,15$, and 20 [10].

In males, it was verified that cotitine, a metabolite from nicotine, is able to cross the hematotesticular barrier, but tissue effects remain unknown [11,12]. There are previous reports of an increase in disomy associated with cigarette smoking (reviewed in Templado [13]), suggesting that molecular cytogenetic approaches are likely to be informative.

Interphase fluorescence in situ hybridization (FISH) has been used with great success to enumerate chromosomal aneuploidies in germ and sperm cells. This technique makes possible a faster and simpler analysis of numerical abnormalities in a high number of cells in a short time period $[14,15]$ and was previously used to evaluate correlations between aneusomies in sperm and exogenous or endogenous factors like fungicides [16], pesticides [17,18], chemotherapy [19], age [20], seminal parameters, reduced sperm count $[21,22]$ and clinical implications in Assisted Reproduction [23,24].

Trisomy 21 (Down syndrome), monosomy X (UllrichTurner syndrome) 47,XXY (Klinefelter) and triple X are the most common numerical chromosomal syndromes in newborns $[25,26]$. Numerical chromosome abnormalities involving chromosomes 13, 16, 21, 22, and sex chromosomes are common causes of spontaneous abortions [27]. However, there are few interphase FISH studies evaluating the meiotic segregation of chromosome 3 in germ cells. The accepted consensus is that large metacentric and submetacentric chromosomes are subject to less meiotic errors due to their large synaptonemal complex, and the relative increase in the number of crossing over events as the bivalents pair. There is only one previous study of chromosome 3 in normosomic controls in which a higher frequency of disomy was observed in comparison to other autosomal chromosomes [28]. This observation suggests that this chromosome may be more prone to segregation anomalies, and may thus also be a more informative overall monitor of smoking-induced meiotic damage. Similarly interphase analysis of the sex chromosomes can distinguish the stage of meiosis that could be more susceptible to smoking-related segregation anomalies. Therefore analysis of sex chromosomes was included as the XY FISH probe can differentiate between abnormalities mostly occurring during meiosis I (responsible for $\mathrm{XY}$ disomy) from those taking place in meiosis II (causing XX and YY disomies) [2,29]. Is noteworthy that some of these XX and YY disomies can take place previously in meiosis I by premature separation of sisters chromatids or all of the disomies can be generated by pre-meiotic events $[29,30]$.

The goal of this study was to determine whether chromosome 3 was subject to meiotic segregation anomalies in sperm derived from male smokers. The approach taken was to investigate the frequency of disomies and diploidies in sperm cells of smokers and in suitably matched control donors, to determine whether there was an association between numerical chromosomal abnormalities and smoking. We selected the most informative combination of DNA probes from chromosomes 3, $\mathrm{X}$, and $\mathrm{Y}$ to monitor the extent and type of meiotic segregation error that could be associated with smoking.

\section{Results}

Chromosome analysis by GTG banding revealed a 46,XY karyotype for all controls and smokers included in the cohort. There was no difference in the mean age between the two groups which were $33 \pm 2.9$ years old (mean $\pm \mathrm{SD}$ ) for controls and $33 \pm 3.1$ for the smoking group.

Table 1 shows comparisons of the seminal parameters for the two groups, smokers and nonsmokers. A significant difference in morphology $(P<0.036)$ was observed, and the smoking group showed a diminished lower number of morphological normal cells $(7.7 \pm 4.5)$ compared with the control group (13.1 \pm 5.1$)$.

A total of 14,014 sperm cells from nonsmokers (control group) and 20,197 from smokers (study group) were evaluated for aneusomy (Figure 1) of the chromosomes $3, \mathrm{X}$, and $\mathrm{Y}$. The data are shown in Table 2.

Statistical analyses were also applied to two subgroups of the smoking group: six individuals (identified as S2, S4, S5, S6, S7, and S8) who smoked more than 20 cigarettes per day and were considered heavy smokers, and four individuals (S1, S3, S9, and S10) who smoked less than 20 cigarettes per day and were classified as light smokers. There were no significant differences between the light and heavy smokers for either the total overall disomy frequency or for each of the chromosomes studied.

\section{Disomy of chromosomes $3, X$, and $Y$}

Abnormalities leading to disomic sperm were present in both smoking and control groups. The control group had a mean of $0.73 \% \pm 0.36$ of total disomy for 
Table 1 Seminal parameters of the controls and smokers

\begin{tabular}{|c|c|c|c|c|c|c|c|c|c|c|c|c|c|c|c|c|c|c|c|}
\hline & \multicolumn{7}{|c|}{ Controls } & \multirow[b]{2}{*}{ Mean \pm SD } & \multicolumn{10}{|c|}{ Smokers } & \multirow[b]{2}{*}{ Mean \pm SD } \\
\hline & C1 & $\mathrm{C} 2$ & $\mathrm{C} 3$ & $\mathrm{C} 4$ & C5 & C6 & $\mathrm{C7}$ & & P1 & P2 & P3 & P4 & P5 & P6 & P7 & P8 & P9 & P10 & \\
\hline Volume (ml) & 2.0 & 3.9 & 3 & 1.2 & 4.5 & 3.2 & 4.1 & $3.1 \pm 1$ & 2.2 & 2.4 & 0.7 & 3 & 3.2 & 5 & 1.7 & 2.2 & 2 & 1.5 & $2.4 \pm 1$ \\
\hline Concentration $\times 10^{6} \mathrm{spz} / \mathrm{ml}$ & 79.5 & 50 & 35 & 100 & 39 & 96.5 & 69 & $67 \pm 26$ & 54.5 & 75.6 & 66.5 & 85 & 26.5 & 74.5 & 19 & 21.5 & 119 & 29 & $57.0 \pm 33$ \\
\hline Total sperm count $\times 10^{6}$ & 159 & 195 & 102 & 120 & 175.5 & 308.8 & 282.8 & $191.9 \pm 78$ & 119 & 181.44 & 46.55 & 255 & 84.8 & 372.5 & 31.45 & 47.3 & 238 & 43.5 & $142.0 \pm 115$ \\
\hline PR & 75 & 44 & 32 & 39 & 27 & 43 & 35 & $42.1 \pm 15$ & 18 & 71 & 24 & 32 & 23 & 29 & 33 & 15 & 27 & 12 & $28.4 \pm 16$ \\
\hline NP & 17 & 24 & 43 & 37 & 42 & 36 & 35 & $33.4 \pm 9$ & 48 & 24 & 42 & 39 & 47 & 41 & 39 & 37 & 37 & 43 & $39.7 \pm 6$ \\
\hline IM & 8 & 32 & 25 & 24 & 31 & 21 & 30 & $24.4 \pm 8$ & 34 & 5 & 34 & 29 & 30 & 30 & 28 & 48 & 36 & 45 & $31.9 \pm 11$ \\
\hline Vitality \% & 94 & 83 & 87 & 86 & 89 & 93 & 87 & $88.4 \pm 4$ & 90 & 98 & 93 & 93 & 90 & 90 & 92 & 89 & 80 & 75 & $89.0 \pm 7$ \\
\hline Morphology \% & 21 & 9 & 8 & 13 & 8 & 17 & 16 & $13.1 \pm 5$ & 4 & 3 & 10 & 15 & 13 & 12 & 8 & 5 & 4 & 3 & $7.7 \pm 4$ \\
\hline
\end{tabular}

PR: Sperm with progressive motility.

NP: Sperm with non-progressive motility.

IM: Sperm immotile.

spz/ml: spermatozoa per $\mathrm{ml}$

SD: standard deviation 

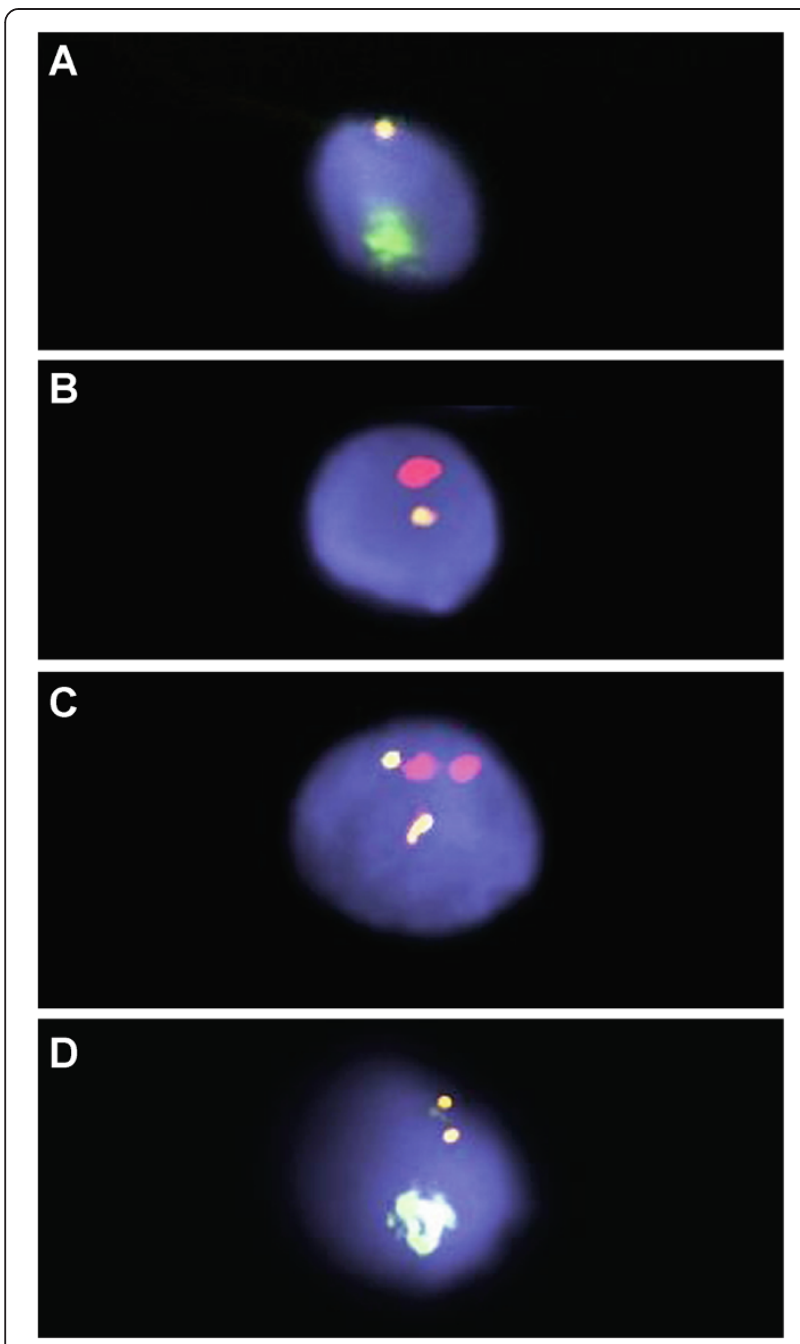

Figure 1 FISH analysis of sperm. A: FISH analysis of sperm showing one chromosome $Y$ (Yqh spectrum green) and chromosome 3 (D3Z1 yellow); B: FISH analysis of sperm showing one chromosome X (DXZ1 spectrum red) and chromosome 3 (D3Z1 yellow); C: FISH analysis of diploid sperm showing two signals for chromosome X (red) and two signals for chromosome 3 (yellow): D: FISH analysis of disomy of chromosome 3 (yellow) and chromosome Y (Yqh spectrum green).

chromosomes $3, \mathrm{X}$, and $\mathrm{Y}$, while the smoking group had a mean of $1.25 \% \pm 0.41$ (Figure 2), with a significant difference between the two groups $(P<0.0001)$.

The frequency of disomy 3 was significantly higher $(P<0.01)$, for the smoking group $(0.35 \pm 0.11)$ in comparison to the nonsmoker controls $(0.15 \pm 0.14)$. Analysis of the sex chromosomes also showed a significant increase $(P<0.0001)$ in the percentage of sperm carrying both sex chromosomes (XY disomy) in the smokers $(0.59 \% \pm 0.26)$, compared to nonsmoker controls $(0.30 \% \pm 0.19)$. Interestingly, when we compared the percentages of disomy for heavy smokers to those individuals classified as light smokers, we observed a slightly higher mean value for heavy smokers $(0.67 \pm 0.29)$ compared to the light smokers $(0.54 \pm 0.25)$. However, there was no statistical difference between these two subgroups. Other disomies involving sex chromosomes (XX and YY disomy) did not show any difference between smokers $(0.16 \% \pm 0.08$ and $0.14 \pm 0.05$ for XX and YY disomy, respectively) and nonsmoker controls $(0.16 \% \pm 0.09$ and $0.14 \% \pm 0.05)$. Individual analysis of samples from both groups showed that XY disomy had the widest range in the smoking group, ranging from $0.3-1.0 \%$. None of the individuals within this group were identified as outliers.

\section{Diploidy}

The presence of disomy for all probes has been considered an indication that sperm may be diploid [14]. Using the set $X / Y / 3$, it was possible to discriminate three types of diploid sperm: XY33, XX33, and YY33. The diploid sperm cells XY33 were found more frequently $(P<0.0002)$ in smokers $(0.53 \% \pm 0.21)$ than in nonsmoker controls $(0.28 \% \pm 0.13)$. The means of diploidy XX33 were $0.03 \% \pm$ 0.05 in smokers and $0.04 \% \pm 0.04$ in controls, with no difference between chromosomes $\mathrm{X}$ or 3 . However, for the diploid sperm YY33, the mean was $0.08 \% \pm 0.08$ in smokers and $0.02 \% \pm 0.03$ in controls, with a significant increase in the smoking group $(P<0.0167)$.

\section{Discussion}

This study indicates that chromosome 3 may be associated with smoking-induced segregation anomalies. We observed a significant increase in total disomy of chromosomes $3, \mathrm{X}$, and $\mathrm{Y}$ in the smoking group in comparison to the control group. This finding was present in both smoking subgroups (light and heavy smokers), suggesting that the smoking habit, independent of the number of cigarettes used, is enough to generate meiotic errors. However, there is a wide set of definitions of light smoking, varying from individuals whom never smoked regularly to individuals that smoke 1-20 cigarettes per day [31,32]. Other authors have reported similar increases in disomy of chromosome 13 [33], disomy YY [34], disomy XX [35] and XY (reviewed [13]) associated with smoking. This present study is the first to describe similar impairment of chromosome 3 segregation in sperm derived from smokers.

The observed significant increase in the percentage of disomy of chromosome 3 suggests that this autosome may be unusually sensitive to the genotoxic damaging effects of tobacco in meiosis in males. Only one previous study has evaluated the segregation of chromosome 3 , in a study unrelated to smoking [36]. Chromosome 3 presented at least three crossing-over regions and a larger synaptonemal complex, relative to the size reported for other chromosomes [37]. Those characteristics would be compatible with a meiotic segregation less prone to errors. However, Downie and colleagues [36] showed a 
Table 2 Percentage (and absolute count) of disomies and diploidies of chromosomes $3, \mathrm{X}$ and $\mathrm{Y}$ in controls and smokers

\begin{tabular}{|c|c|c|c|c|c|c|c|c|c|c|c|}
\hline & \multicolumn{7}{|l|}{ Disomies } & \multicolumn{4}{|l|}{ Diploidies } \\
\hline & X3 & Y3 & $\mathrm{XY3}$ & $\mathrm{XX3}$ & YY3 & X33 & Y33 & XY33 & XX33 & YY33 & Total \\
\hline \multicolumn{12}{|l|}{ Controls } \\
\hline C1 & $50.57(1,024)$ & 48.54 (983) & $0.20(4)$ & $0.15(3)$ & $0.15(3)$ & $0.05(1)$ & $0.10(2)$ & $0.20(4)$ & $0(0)$ & $0.05(1)$ & $100(2,025)$ \\
\hline C2 & $44.30(886)$ & $54.25(1,085)$ & $0.65(13)$ & $0.25(5)$ & $0.20(4)$ & $0(0)$ & $0.05(1)$ & $0.25(5)$ & $0.05(1)$ & $0.00(0)$ & $100(2,000)$ \\
\hline C3 & 49.61 (957) & $49.30(951)$ & $0.16(3)$ & $0.05(1)$ & $0.10(2)$ & $0.05(1)$ & $0.16(3)$ & $0.41(8)$ & $0.10(2)$ & $0.05(1)$ & $100(1,929)$ \\
\hline C4 & $50.57(1,015)$ & $49.08(985)$ & $0.15(3)$ & $0.05(1)$ & $0.05(1)$ & $0.05(1)$ & $0(0)$ & $0.05(1)$ & $0(0)$ & $0(0)$ & $100(2,007)$ \\
\hline C5 & $52.00(1,041)$ & 46.35 (928) & $0.45(9)$ & $0.30(6)$ & $0.10(2)$ & $0.30(6)$ & $0.15(3)$ & $0.35(7)$ & $0(0)$ & $0(0)$ & $100(2,002)$ \\
\hline C6 & 49.48 (999) & $49.63(1,002)$ & $0.15(3)$ & $0.15(3)$ & $0.15(3)$ & $0.05(1)$ & $0.05(1)$ & $0.25(5)$ & $0.05(1)$ & $0.05(1)$ & $100(2,019)$ \\
\hline C7 & $45.13(917)$ & $53.79(1,093)$ & $0.25(5)$ & $0.15(3)$ & $0.20(4)$ & $0(0)$ & $0.05(1)$ & $0.39(8)$ & $0.05(1)$ & $0.00(0)$ & $100(2,032)$ \\
\hline Mean $(\%) /$ Total & $48.52(6,839)$ & $50.40(7,027)$ & $0.30(40)$ & $0.16(22)$ & $0.14(19)$ & $0.08(10)$ & $0.08(11)$ & $0.28(38)$ & $0.04(5)$ & $0.02(3)$ & $(14,014)$ \\
\hline \multicolumn{12}{|l|}{ Smokers } \\
\hline S1 & $48.03(965)$ & $50.67(1,018)$ & $0.40(8)$ & $0.10(2)$ & $0.20(4)$ & $0.14(3)$ & $0.10(2)$ & $0.25(5)$ & $0.05(1)$ & $0.05(1)$ & $100(2,009)$ \\
\hline S2 & 48.69 (985) & $50.02(1,012)$ & $0.30(6)$ & $0.15(3)$ & $0.10(2)$ & $0.15(3)$ & $0.10(2)$ & $0.40(8)$ & $0(0)$ & $0.10(2)$ & $100(2,023)$ \\
\hline S3 & $49.36(1,009)$ & $49.46(1,011)$ & $0.44(9)$ & $0.10(2)$ & $0.10(2)$ & $0.10(2)$ & $0.15(3)$ & $0.29(6)$ & $0(0)$ & $0(0)$ & $100(2,044)$ \\
\hline S4 & $49.80(1,011)$ & 48.77 (990) & $0.34(7)$ & $0.25(5)$ & $0.10(2)$ & $0.20(4)$ & $0.10(2)$ & $0.44(9)$ & $0(0)$ & $0(0)$ & $100(2,030)$ \\
\hline S5 & $47.10(950)$ & $51.02(1,029)$ & $0.55(11)$ & $0.10(2)$ & $0.20(4)$ & $0.20(4)$ & $0.15(3)$ & $0.69(14)$ & $0(0)$ & $0(0)$ & $100(2,017)$ \\
\hline S6 & 48.60 (990) & $49.48(1,008)$ & $0.59(12)$ & $0.10(2)$ & $0.20(4)$ & $0.20(4)$ & $0.25(5)$ & $0.49(10)$ & $0.05(1)$ & $0.05(1)$ & $100(2,037)$ \\
\hline S7 & $47.04(945)$ & $51.42(1,033)$ & $0.50(10)$ & $0.20(4)$ & $0.10(2)$ & $0.10(2)$ & $0.15(3)$ & $0.45(9)$ & $0(0)$ & $0.05(1)$ & $100(2,009)$ \\
\hline S8 & 48.23 (969) & 49.03 (985) & $1.00(20)$ & $0.25(5)$ & $0.20(4)$ & $0.15(3)$ & $0.35(7)$ & $0.55(11)$ & $0.10(2)$ & $0.15(3)$ & $100(2,009)$ \\
\hline S9 & 49.63 (997) & $47.98(964)$ & $0.90(18)$ & $0.10(2)$ & $0.15(3)$ & $0.15(3)$ & $0.20(4)$ & $0.75(15)$ & $0(0)$ & $0.15(3)$ & $100(2,009)$ \\
\hline S10 & 48.51 (975) & 48.26 (970) & $0.95(19)$ & $0.30(6)$ & $0.10(2)$ & $0.30(6)$ & $0.25(5)$ & $0.95(19)$ & $0.15(3)$ & $0.25(5)$ & $100(2,010)$ \\
\hline Mean (\%)/Total & $48.50(9,796)$ & $49.61(10,020)$ & 0.59 (120) & $0.16(33)$ & $0.14(29)$ & $0.17(34)$ & $0.18(36)$ & $0.52(106)$ & $0.03(7)$ & $0.08(16)$ & $100(20,197)$ \\
\hline
\end{tabular}

high inter-individual variation in the frequency of disomy of chromosome 3 . They also observed that the frequency of disomy 3 of $0.20 \%$ was more than three times higher than other autosomal chromosomes such as $7(0.05 \%)$ and $16(0.06 \%)$. This elevated frequency was also found in our study, with $0.15 \%$ of disomy 3 observed even in the control group. These preliminary data suggest that smoking may preferentially affect the meiotic segregation of chromosome 3 , and imply that this chromosome is subject to more inter-individual variation in the population.

The exact mechanism to explain the association between smoking and increased aneuploidy in sperm is presently unknown. Some reports have shown an increase of

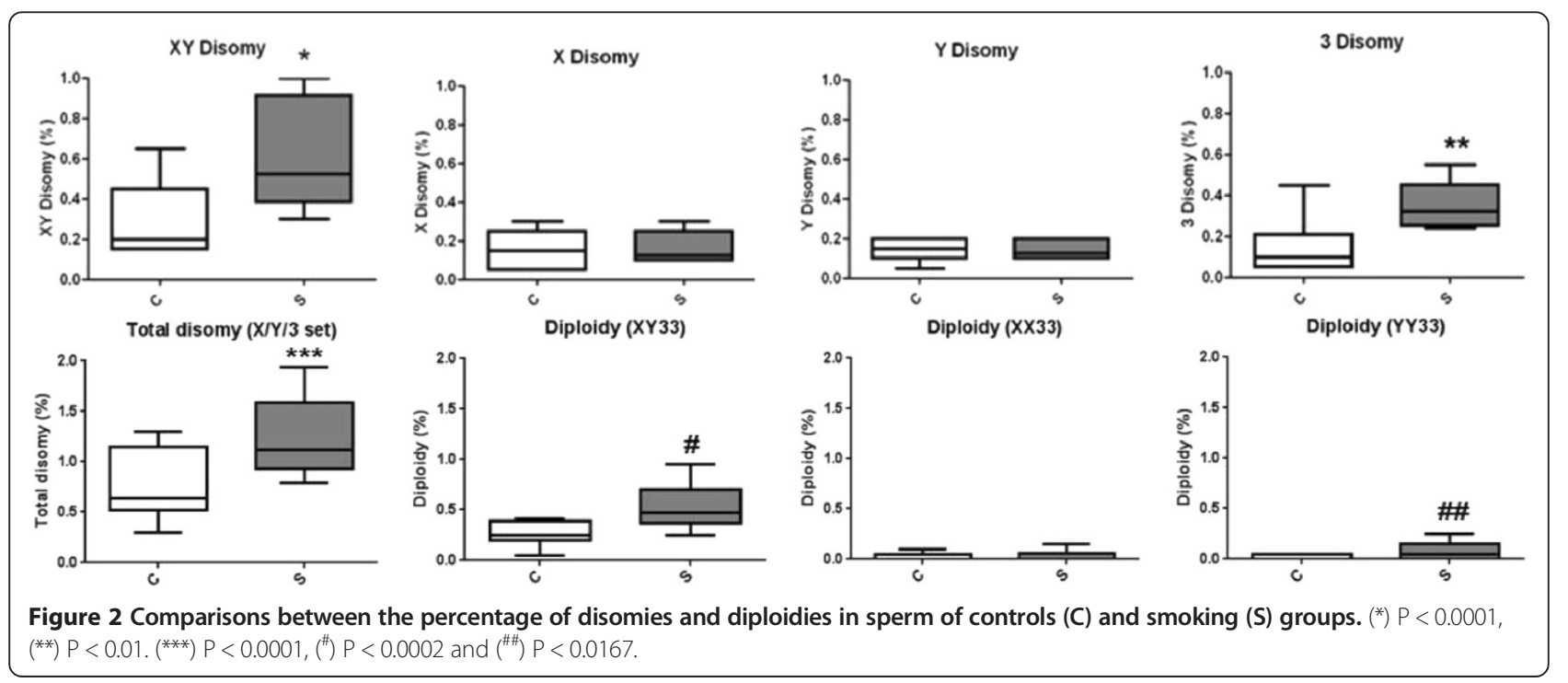


oxidant substances and decreased antioxidant enzymes, providing a genotoxic environment for germ cells [38]. Smoking may also lead to deterioration of the sperm membrane, allowing greater interaction of extracellular substances with the nucleus [39]. Cotitine, a metabolite from nicotine, is able to cross the hematotestis barrier, and like other alkaloids, the drug can interact with the spindle [40]. The capacity of nicotine and others alkaloids to induce aneuploidy has also been confirmed in experimental systems [5,40].

We also identified a higher number of morphologically abnormal sperm cells in the smoking group than the controls $(P<0.036)$. We also observed seven smokers with asthenozoospermia and an apparent reduction in the total number of motile sperm, but we did not find any statistical differences when the smoking group was compared to controls for both progressive and total motility. Previously, Gaur and colleagues [41] verified that the motility was reduced even in light smokers compared to nonsmokers. Also, they found a higher level of teratozoospermia in individuals who smoke more than 41 cigarettes per day. Our analysis confirmed that the smokers in our cohort had a reduction of the proportion of morphologically normal sperm that directly correlated with their fertilization success rate. Another study has described an inverse correlation between semen concentration and cell motility with sex chromosome disomies (XY disomy) [42]. Thus impairment of semen parameters and meiotic segregation anomalies could be due to both constitutive and exogenous factors. We excluded the oligozoospermic men based on the observations of Sarrate and colleagues [24] who evaluated chromosomal segregation in sperm of more than 300 infertile men and concluded that oligozoospermy was the only seminal parameter that correlated with the percentage of chromosome abnormalities.

The comparison of XY disomy between the two groups showed a significant increase in the smoking group. In contrast, the frequencies of disomies of XX and YY were not elevated in the smoking group. These findings suggest that pairing of particular homologues or specific events in the cell cycle are more prone to be disturbed by smoking. In this case, the segregation in meiosis I was more affected by tobacco consumption, rather than the separation of sister chromatids. Evaluating 11 smokers, Rubes and colleagues [34] verified an increase only in disomy YY, but not in XY or XX, while Robbins [35] observed an increase in disomy XX in smokers. In another study, no difference in sex chromosome disomies was identified between smokers and nonsmokers [33].

Our data suggest that errors in meiosis I in smokers are more frequent than in meiosis II. A possible explanation for this susceptibility in meiosis I in the sex chromosome pair could be the small number of chiasmas and the absence of a complete synaptonemal complex, two essential characteristics related to correct meiotic segregation [37,43]. Recently, McAuliffe and colleagues [42] also showed that a higher frequency of XY disomy was associated with low levels of concentration of sperm in ejaculated semen, while no difference was found in $\mathrm{XX}$ or $\mathrm{YY}$ disomies.

The frequency of diploid sperm cells with both sex chromosomes (identified as diploidy XY33) was higher in the smoking group. Rubes and colleagues [34] also identified an increase of diploid sperm cells in a smoking group, but their report did not specify the type of diploidy. We have observed that the frequency of XX33 and YY33 sperm was not higher in smokers than diploidy $\mathrm{XY33}$, suggesting once more that meiosis I is more susceptible to some exogenous agent.

\section{Conclusion}

In conclusion, our study has shown that chromosome 3 may be susceptible to smoking-related segregation anomalies. Our analysis using $\mathrm{X} / \mathrm{Y}$ probes suggests that errors can occur in both meiosis I and II. Thus the overall elevated frequency of numerical chromosomal anomalies in the sperm of smokers compared to control fertile men is in keeping with the emerging literature of the potential damaging effects of tobacco toxins on chromosomal segregation mechanisms, and this could be associated with an elevated risk of infertility. Ideally male smokers should be strongly encouraged to cease smoking. We suggest that evaluative protocols for assisted reproductive technology could consider FISH analysis of sperm when the male partner continues to smoke.

\section{Methods}

\section{Cohort}

This study included two main groups. The control group was composed of seven fertile males in the age range of $31-38$ years $(33 \pm 2.9)$. The smoking group included ten smokers in the age range of $23-48$ years $(33 \pm 3.1)$. All males in both groups (controls and smokers) were fathers of at least one child in the last two years. None of non-smokers from the control group were ex-smokers and none of the controls or smokers had occupational exposure to pesticides or fungicides or had been submitted to hormone therapy or chemotherapy. Both groups include men with light alcohol consumption (1-4 drinks per month) except for one smoking individual, identified as S10, who was defined as an abstainer (less than 12 drinks per year).

\section{Ethical approval}

The smoking and control groups were informed about the study, and all the patients signed the consent form approved by the Hospital Ethics Committee of Ribeirão 
Preto Medical School, University of Sao Paulo (process HCRP 6092/2008).

\section{Karyotype}

A peripheral blood culture of all men from both groups was performed according to standard cytogenetic methods. Chromosomal analysis by GTG banding was carried out in 100 metaphases for mosaicism exclusion.

\section{Spermogram}

Each sperm sample was collected in a sterile collector and an aliquot was used for spermogram analysis and FISH. Seminal parameters including concentration, morphology, motility, and vitality of sperm were analyzed accordingly to World Health Organization (WHO) [44]. All controls used in this study had seminal parameters that were in keeping with the reference limits suggested by WHO [44]. The parameters considered for the controls were 39 (range 33-46) $\times 10^{6}$ per ejaculate for total sperm number, $15(12-16) \times 10^{6}$ per $\mathrm{ml}$ for sperm concentration, $40 \%$ (38$42 \%)$ for total motility $($ Progressive $=$ PR; Non-progressive $=$ NP), 58\% (55-63\%) for vitality (\% of live spermatozoa) and $4 \%(3.0-4.0 \%)$ for sperm morphology (\% of normal forms).

\section{Fluorescence in situ hybridization in sperm}

Sperm decondensation and hybridization procedures were performed as described by Juchniuk de Vozzi et al. [45]. The slides were made with $5 \mu \mathrm{l}$ of the sample and stored at $-20^{\circ} \mathrm{C}$.

Multicolor interphase FISH studies of sperm preparations were performed using a probe set for each sample: a triple-color FISH with specific probes for chromosomes X (CEP X, Locus DXZ1), Y (SE Y class q arm, Yqh), and 3 (SE 3, Locus D3Z1 and SE 3, Locus D3Z) from Kreatech Diagnostics, USA. Two chromosome 3 probes were combined to generate a yellow color. Hybridization efficiency was $97.5 \%$, ranging between $97 \%$ and $98 \%$.

\section{Sperm disomy and diploidy scoring}

The FISH slides were coded and enumerated by two independent analysts using an Olympus BX-40 microscope (Olympus, UK) and Applied Imaging software (Applied Imaging, UK).

Scoring criteria were based on Downie and colleagues [14]. The selected sperm cells did not exhibit overlaps and were symmetrically oval with normal tails. Scored signals presented an equal size and the same fluorescence intensity and were clearly located within the nucleus. The sperm classified as disomic showed two signals of similar size, and both were separated by at least half a signal domain. At least 2,000 sperm cells were analyzed per individual.

\section{Statistical analysis}

The data was analyzed by Statistical Analysis System software (SAS) using GENMOD which fits a generalized linear model to the data by a maximum likelihood estimation, considering the analyzed frequencies distribution. To compare controls and smokers, the analysis was performed using a two-parameter gamma test for all phenotypic variables related to sperm (motility, concentration, vitality, and morphology), which followed a continuous probability distribution. Poisson distribution was considered to analyze the frequencies of disomies and diploidies in sperm because these discontinuous variables were not normally distributed and occurred as independent events. All data are shown as mean \pm SD.

\section{Competing interests}

There were no competing interests.

\section{Authors' contributions}

CSP: Participation in study design, sample collection and pre-treatment, FISH execution and analysis, critical discussion, and manuscript drafting. MSJdV: Participation in study design, sample collection and pre-treatment, FISH execution and analysis, and critical discussion. SAS: Classical cytogenetics protocols and chromosomal analysis. MACV: Spermogram analysis. CCPP: Statistical analysis and critical discussion. JS: Supervision, critical discussion, and manuscript corrections. LM: Supervision, study design, critical discussion, and manuscript drafting and corrections. All authors read and approved the final manuscript.

\section{Acknowledgements}

We acknowledge Dr. Maisa Yoshimoto for her assistance with molecular cytogenetic analysis and Dr. Aparecido D. da Cruz for thoughtful

suggestions. The authors gratefully acknowledge the participation of the volunteers and the members of the Human Reproduction Division of the Department of Gynecology and Obstetrics, Ribeirao Preto Medical School, University of Sao Paulo.

\section{Funding}

This work has been supported by the National Research Council (CNPq -Conselho Nacional de Pesquisa, Brazil) and the Foundation of Support to Teaching, Research and Assistance of Clinics Hospital, Ribeirao Preto Medical School, University of Sao Paulo (FAEPA-HCFMRP).

\section{Author details}

${ }^{1}$ Department of Genetics, Ribeirao Preto Medical School, University of São Paulo, 3900 Bandeirantes Avenue, Zip code 14049-900 Ribeirao Preto, SP, Brazil. '2Department of Gynecology and Obstetrics, Ribeirao Preto Medical School, University of São Paulo, 3900 Bandeirantes Avenue, Ribeirão Preto, SP, Brazil. 'Department of Pathology and Molecular Medicine, Queen's University, 88 Stuart Street, Kingston, ON, Canada.

Received: 19 May 2014 Accepted: 12 August 2014

Published online: 12 September 2014

\section{References}

1. Hassold T, Abruzzo M, Adkins K, Griffin D, Merrill M, Millie E, Saker D, Shen J, Zaragoza M: Human aneuploidy: incidence, origin, and etiology. Environ Mol Mutagen 1996, 28:167-175

2. Hassold T, Hunt P: To err (meiotically) is human: the genesis of human aneuploidy. Nat Rev Genet 2001, 2:280-291.

3. Bosch M, Rajmil O, Egozcue J, Templado C: Linear increase of structural and numerical chromosome 9 abnormalities in human sperm regarding age. Eur J Hum Genet 2003, 11:754-759.

4. WHO: Global Status Report on Noncommunicable Diseases. 1st edition. Geneva: WHO; 2011 
5. Fraga CG, Motchnik PA, Wyrobek AJ, Rempel DM, Ames BN: Smoking and low antioxidant levels increase oxidative damage to sperm DNA. Mutat Res 1996, 351:199-203.

6. Husgafvel-Pursiainen K: Genotoxicity of environmental tobacco smoke: a review. Mutat Res 2004, 567:427-445.

7. Sepaniak S, Forges T, Gerard H, Foliguet B, Bene MC, Monnier-Barbarino P. The influence of cigarette smoking on human sperm quality and DNA fragmentation. Toxicology 2006, 223:54-60.

8. Honein MA, Paulozzi $\amalg$, Watkins ML: Maternal smoking and birth defects: validity of birth certificate data for effect estimation. Public Health Rep 2001, 116:327-335

9. Hackshaw A, Rodeck C, Boniface S: Maternal smoking in pregnancy and birth defects: a systematic review based on 173687 malformed cases and 11.7 million controls. Hum Reprod Update 2011, 17:589-604.

10. Demirhan O, Demir C, Tunç E, nandıklığlu N, Sütcü E, Sadıkoğlu N, Ozcan $B$ : The genotoxic effect of nicotine on chromosomes of human fetal cells: the first report described as an important study. Inhal Toxicol 2011 23:829-834

11. Vine MF, Hulka BS, Margolin BH, Truong YK, Hu PC, Schramm MM, Griffith $J D, M c C a n n$ M, Everson RB: Cotinine concentrations in semen, urine, and blood of smokers and nonsmokers. Am J Public Health 1993, 83:1335-1338.

12. Wong WY, Thomas CM, Merkus HM, Zielhuis GA, Doesburg WH, SteegersTheunissen RP: Cigarette smoking and the risk of male factor subfertility: minor association between cotinine in seminal plasma and semen morphology. Fertil Steril 2000, 74:930-935.

13. Templado C, Uroz L, Estop A: New insights on the origin and relevance of aneuploidy in human spermatozoa. Mol Hum Reprod 2013, 19:634-643.

14. Downie SE, Flaherty SP, Matthews CD: Detection of chromosomes and estimation of aneuploidy in human spermatozoa using fluorescence in-situ hybridization. Mol Hum Reprod 1997, 3:585-598.

15. Shi Q, Martin RH: Aneuploidy in human spermatozoa: FISH analysis in men with constitutional chromosomal abnormalities, and in infertile men. Reproduction 2001, 121:655-666.

16. Härkönen K, Viitanen T, Larsen SB, Bonde JP, Lähdetie J: Aneuploidy in sperm and exposure to fungicides and lifestyle factors. ASCLEPIOS. A European Concerted Action on Occupational Hazards to Male Reproductive Capability. Environ Mol Mutagen 1999, 34:39-46.

17. Xia Y, Bian Q, Xu L, Cheng S, Song L, Liu J, Wu W, Wang S, Wang X: Genotoxic effects on human spermatozoa among pesticide factory workers exposed to fenvalerate. Toxicology 2004, 203:49-60

18. Perry MJ: Effects of environmental and occupational pesticide exposure on human sperm: a systematic review. Hum Reprod Update 2008 14:233-242.

19. Martin RH, Ernst S, Rademaker A, Barclay L, Ko E, Summers N: Analysis of sperm chromosome complements before, during, and after chemotherapy. Cancer Genet Cytogenet 1999, 108:133-136.

20. Sloter ED, Marchetti F, Eskenazi B, Weldon RH, Nath J, Cabreros D, Wyrobek AJ: Frequency of human sperm carrying structural aberrations of chromosome 1 increases with advancing age. Fertil Steril 2007, 87:1077-1086.

21. Collodel G, Moretti E: Sperm morphology and aneuploidies: defects of supposed genetic origin. Andrologia 2006, 38:208-215.

22. Collodel G, Capitani S, Baccetti B, Pammolli A, Moretti E: Sperm aneuploidies and low progressive motility. Hum Reprod 2007, 22:1893-1898.

23. Rodrigo L, Peinado V, Mateu E, Remohí J, Pellicer A, Simón C, Gil-Salom M, Rubio C: Impact of different patterns of sperm chromosomal abnormalities on the chromosomal constitution of preimplantation embryos. Fertil Steril 2010, 94:1380-1386.

24. Sarrate Z, Vidal F, Blanco J: Role of sperm fluorescent in situ hybridization studies in infertile patients: indications, study approach, and clinical relevance. Fertil Steril 2010, 93:1892-1902.

25. Maeda T, Ohno M, Matsunobu A, Yoshihara K, Yabe N: A cytogenetic survey of 14,835 consecutive liveborns. Jinrui Idengaku Zasshi 1991, 36:117-129.

26. Roizen NJ, Patterson D: Down's syndrome. Lancet 2003, 361:1281-1289.

27. Nagaishi M, Yamamoto T, linuma K, Shimomura K, Berend SA, Knops J: Chromosome abnormalities identified in 347 spontaneous abortions collected in Japan. J Obstet Gynaecol Res 2004, 30:237-241.

28. Templado C, Bosch M, Benet J: Frequency and distribution of chromosome abnormalities in human spermatozoa. Cytogenet Genome Res 2005, 111:199-205.
29. Hultén MA, Patel SD, Westgren M, Papadogiannakis N, Jonsson AM, Jonasson J, Iwarsson E: On the paternal origin of trisomy 21 Down syndrome. Mol Cytogenet 2010, 3:4

30. Hultén MA, Patel SD, Tankimanova M, Westgren M, Papadogiannakis N, Jonsson AM, Iwarsson E: On the origin of trisomy 21 Down syndrome. Mol Cytogenet 2008, 1:21

31. Husten CG: How should we define light or intermittent smoking? Does it matter? Nicotine Tob Res 2009, 11:111-121.

32. Mucha L, Stephenson J, Morandi N, Dirani R: Meta-analysis of disease risk associated with smoking, by gender and intensity of smoking. Gend Med 2006, 3:279-291.

33. Shi Q, Ko E, Barclay L, Hoang T, Rademaker A, Martin R: Cigarette smoking and aneuploidy in human sperm. Mol Reprod Dev 2001, 59:417-421.

34. Rubes J, Lowe X, Moore D, Perreault S, Slott V, Evenson D, Selevan SG, Wyrobek AJ: Smoking cigarettes is associated with increased sperm disomy in teenage men. Fertil Steril 1998, 70:715-723.

35. Robbins WA, Vine MF, Truong KY, Everson RB: Use of fluorescence in situ hybridization (FISH) to assess effects of smoking, caffeine, and alcohol on aneuploidy load in sperm of healthy men. Environ Mol Mutagen 1997 30:175-183

36. Downie SE, Flaherty SP, Swann NJ, MatthewS CD: Estimation of aneuploidy for chromosomes $3,7,16, X$ and $Y$ in spermatozoa from 10 normospermic men using fluorescence in-situ hybridization. Mol Hum Reprod 1997, 3:815-819.

37. Sun F, Oliver-Bonet M, Liehr T, Starke H, Ko E, Rademaker A, Navarro J, Benet J, Martin RH: Human male recombination maps for individual chromosomes. Am J Hum Genet 2004, 74:521-531.

38. Pasqualotto FF, Umezu FM, Salvador M, Borges E, Sobreiro BP, Pasqualotto EB: Effect of cigarette smoking on antioxidant levels and presence of leukocytospermia in infertile men: a prospective study. Fertil Steril 2008, 90:278-283.

39. Belcheva A, Ivanova-Kicheva M, Tzvetkova P, Marinov M: Effects of cigarette smoking on sperm plasma membrane integrity and DNA fragmentation. Int J Androl 2004, 27:296-300.41.

40. Jordan A, Hadfield JA, Lawrence NJ, McGown AT: Tubulin as a target for anticancer drugs: agents which interact with the mitotic spindle. Med Res Rev 1998, 18:259-296.

41. Gaur DS, Talekar M, Pathak VP: Effect of cigarette smoking on semen quality of infertile men. Singapore Med J 2007, 48:119-123.

42. McAuliffe ME, Williams PL, Korrick SA, Dadd R, Perry MJ: The association between sperm sex chromosome disomy and semen concentration, motility and morphology. Hum Reprod 2012, 27:2918-2926.

43. Ferguson KA, Wong EC, Chow V, Nigro M, Ma S: Abnormal meiotic recombination in infertile men and its association with sperm aneuploidy. Hum Mol Genet 2007, 16:2870-2879.

44. WHO: WHO: WHO Laboratory Manual for the Examination and Processing of Human Semen. 5th edition. Geneva: WHO Press; 2010:286

45. de Vozzi MS J, Santos SA, Pereira CS, Cuzzi JF, Laureano LA, Franco JG, Martelli L: Meiotic segregation and interchromosomal effect in the sperm of a double translocation carrier: a case report. Mol Cytogenet 2009, 2:24.

doi:10.1186/s13039-014-0058-7

Cite this article as: Pereira et al:: Smoking-induced chromosomal segregation anomalies identified by FISH analysis of sperm. Molecular Cytogenetics 2014 7:58.

\section{Submit your next manuscript to BioMed Central and take full advantage of:}

- Convenient online submission

- Thorough peer review

- No space constraints or color figure charges

- Immediate publication on acceptance

- Inclusion in PubMed, CAS, Scopus and Google Scholar

- Research which is freely available for redistribution 